\title{
A cadeia de Pecuária de Corte no Brasil: evolução e tendências
}

The beef cattle chain in Brazil: evolution and trends

Thiago Bernardino de Carvalho ${ }^{1 *}$; Sérgio De Zen²

${ }^{1}$ Cepea/Esalq/USP - Doutor em Administração e Pesquisador Cepea - Rua Professor Salvador Silveira de Moraes, 229. Casa 655, Jardim Noiva da Colina - CEP: 13420-705, Piracicaba (SP), Brasil

${ }^{2}$ Esalq/USP - Professor Doutor LES- ESALQ/USP - Avenida Centenário, 1080, São Dimas - CEP: 13416-000, Piracicaba (SP), Brasil

\section{Resumo}

As atividades relativas à pecuária bovina de corte no Brasil possuem grande destaque, dado que o país possui o maior rebanho comercial do mundo, sendo o segundo maior produtor e o maior exportador mundial de carne bovina. A principal característica no desenvolvimento dessa atividade no País é a heterogeneidade nos sistemas de produção e nos mecanismos de gestão e de comercialização do gado. A Pecuária brasileira tem passado por grandes mudanças nos últimos anos. Na indústria, a profissionalização levou as empresas à abertura de capital, a internacionalização, a diversificação das atividades e produtos e, como consequência num mercado oligopolizado, à concentração do setor. Dentro da porteira, o setor produtivo também tem conseguido avanço, no emprego de tecnologias, diversificação de atividades e novas formas de comercialização, com a indústria de insumos e os frigoríficos. O futuro do mercado de gado de corte, assim como para todo o agronegócio brasileiro é promissor, devido principalmente a disponibilidade de terra e água presentes no território nacional para se produzir carne e ofertar ao mundo.

Palavras-chave: bovinocultura de corte, mercado, comercialização

\begin{abstract}
The activities related to cattle in Brazil are very important, given that the country has the largest commercial herd in the world, being the second largest producer and the world's largest exporter of beef. The main characteristic in the development of this activity in the country is the heterogeneity in the systems of production and in the mechanisms of management and commercialization of cattle. The Brazilian cattle has undergone major changes in recent years. In the industry, professionalization led companies to open up capital, internationalization, diversification of activities and products and, as a consequence, in an oligopolized market, to the concentration of the sector. In the farms, the productive sector has also achieved progress, in the use of technologies, diversification of activities and new forms of commercialization, with the input industry and the slaughterhouses. The future of the beef cattle market, as well as for all Brazilian agribusiness is promising, mainly due to the availability of land and water present in the national territory to produce meat and offer to the world.
\end{abstract}

Keywords: beef cattle, market, commercialization

\section{Introdução}

O sistema agroindustrial da pecuária é uma das atividades mais importantes do agronegócio nacional - em 2015, representou 6,82\% do PIB brasileiro (Cepea, 2016b). As atividades relativas à pecuária bovina de corte possuem destaques, dado que o País possui o maior rebanho comercial do mundo, sendo o segundo maior produtor e o maior exportador mundial de carne bovina.

\footnotetext{
* Autor correspondente: <tbcarval@cepea.org.br>

Enviado: 19 jan. 2017

Aprovado: 07 fev. 2017
} 
A atividade pecuária realizada dentro da porteira foi responsável pela geração de US\$ 31,4 bilhões, o equivalente a $18,7 \%$ do PIB gerado pela cadeia em questão (ABIEC, 2011). Nesse segmento, destaca-se que o Brasil detinha, em 2015, 215,2 milhões de cabeças de bovinos (IBGE, 2016). A principal característica no desenvolvimento dessa atividade no País é a heterogeneidade nos sistemas de produção e nos mecanismos de gestão e de comercialização do gado. Coexistem dois subsistemas de produção bastante distintos. O primeiro é de alta qualidade, caracterizado pela adoção de tecnologia avançada e padrões eficientes de gestão e de comercialização. O segundo, de baixa qualidade, baseia-se na produção extensiva, pequena intensidade tecnológica e padrões precários de gestão e de comercialização do gado bovino.

O último grupo, de baixa produtividade, traz ao setor um forte impacto ambiental. Nos últimos anos, o impacto que a produção de carne bovina brasileira causado no ambiente natural tem atraído alguma atenção, em particular pela carne produzida perto da floresta amazônica e pela abertura de novas áreas.

Estima-se que de $50 \%$ a $70 \%$ das pastagens no Brasil apresentam algum grau de degradação (Dias-Filho, 2011), o que poderia ser atribuído ao manejo inadequado das pastagens e ao pouco ou nenhum uso de adubação para substituir a fertilidade natural. Pelo lado da indústria, o custo ambiental gerado pelo transporte da carne de regiões produtoras aos mercados consumidores também chama a atenção de ambientalistas. Como resultado, a resolução dos problemas de eficiência no setor da carne e de infraestrutura é considerada de extrema importância para reduzir os impactos ambientais.

Por fim, a parte social da cadeia torna-se importante na análise da atividade e das relações entre produtores e indústria. Estima-se que a atividade emprega mais de 1,5 milhão de pessoas dentro da porteira e beneficia cerca de 5 milhões de pessoas que dependem dessa renda (Cepea, 2016c). Na indústria, esse número não é tão distante, ficando próximo ao de um milhão de pessoas empregadas. Dessa forma, a relação entre estes dois elos (sem considerar indústria de insumos e varejo) gera emprego, renda e desenvolvimento para uma região sendo fundamental a posição de ambos na cadeia.

\section{Indicadores}

\section{Setor Produtivo - Dentro da Porteira}

A pecuária bovina de corte está presente no cenário econômico nacional, desde a época colonial. Nas últimas décadas, a pecuária bovina de corte desenvolveu-se 
através da expansão da fronteira agrícola, com a incorporação de novas terras, sendo a maioria desprovida de infraestrutura e tendo desgaste do solo pelo sistema intensivo de produção de grãos. A produção nacional sempre se caracterizou pelo sistema extensivo. Nos últimos anos, com a incorporação de novas tecnologias que visam ao aumento da produtividade, cresceram os sistemas intensivos de produção em algumas regiões, os chamados confinamentos ou semi-confinamentos.

Nos anos 90 e início de novo século, observa-se uma pecuária nacional com altos índices de produtividade. A atividade vem evoluindo nos últimos anos, com o emprego de tecnologia e aumento de produtividade dentro das propriedades. A Figura 1 mostra uma comparação nos anos de 2003 e 2013. As taxas de lotação de cada uma das regiões destacadas vêm aumentando. No entanto, a elevação dessas taxas não representa necessariamente aumento na produtividade de carne, que é sobre o ganho de peso vivo total por hectare. No entanto, no caso do Brasil, uma vez que a produtividade em geral é muito baixa, a taxa de estoque pode ser aumentada sem causar um déficit nutricional nos animais.

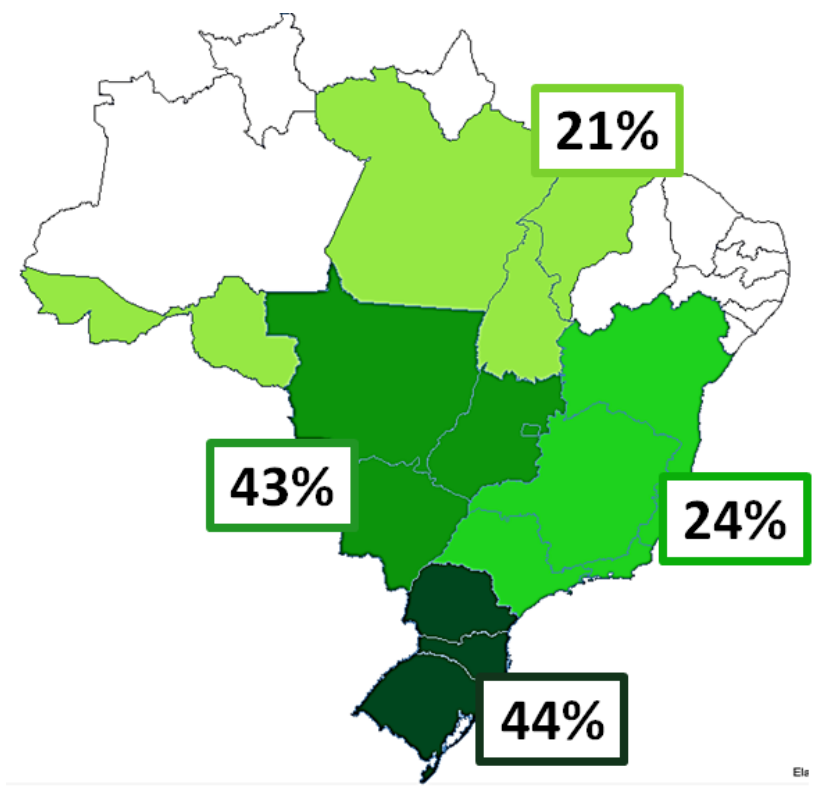

Figura 1. Variação na taxa de lotação em fazendas típicas de carne bovina comparação entre 2003 e 2013

Fonte: Cepea (2016c)

Vale ressaltar que as secas dos anos de 2013 e de 2014 reduziram a oferta de animais para a reposição da recria. Isso elevou o preço de comercialização do bezerro e a margem do criador, que, entre 2014 e 2015, mais que dobrou. Esses dois fatores 
(secas da safra 13/14 e aumento da margem do criador) afetaram a venda de insumos, principalmente sementes. Na safra $13 / 14$, as vendas foram prejudicadas pela redução das chuvas. No ano seguinte, ocorreu o oposto, devido a chuvas regulares e ao maior poder de compra do criador. Nesse contexto, o preço das sementes também subiu. No quatro trimestre de 2015, nos estados do Sul, Sudeste e Centro-Oeste, a abundância de chuvas motivou as vendas tanto de sementes forrageiras como de adubos. Isso mostrou uma tendência de aumento nos investimentos na pecuária dentro da porteira.

Outro fator recente na pecuária nacional foi o aumento de áreas das fazendas, principalmente de cria e de ciclo completo, que com produtividade e receita maiores devido a preços altos dos últimos anos favorecem a absorção de áreas menos produtivas, sejam da mesma atividade e/ou de outras que passaram por crise ou mudanças do sistema de produção.

\section{Confinamento}

No segundo semestre, o fator principal de formação de preço, aliado ao consumo doméstico e externo, foi volume de animais em confinamento. Esta atividade esteva muito atrelada por um lado aos custos da reposição (bezerro e boi magro) e alimentação (milho principalmente) (Figura 2), e por outro lado, os preços futuros do segundo semestre.
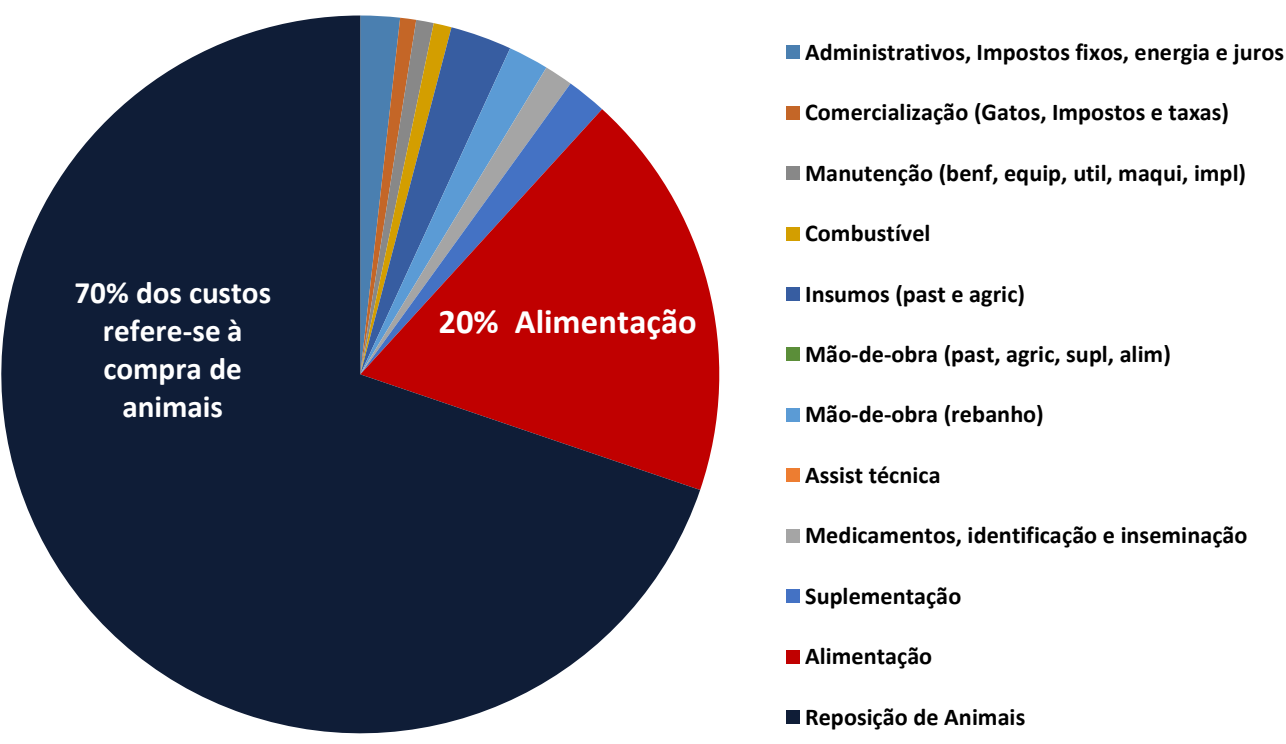

Figura 2. Composição média dos custos de confinamento de pecuária de corte no Brasil para o ano de 2016

Fonte: Cepea (2016c) 
Segundo a Associação Nacional dos Confinadores [Assocon] (2016), o volume de animais confinados em 2015 ficou pouco abaixo de 731 mil cabeças, ante as 769 mil do ano anterior. No Brasil, o total de animais confinados gira em torno de 4 milhões de cabeças.

Muitos produtores usam este sistema para dar acabamento a seus animais e ganhar um prêmio junto a indústria. Outros produtores utilizam como forma de agregar valor à produção de grãos e outros pela falta de espaço para uma produção extensiva.

Entretanto, esse sistema ainda oscila em termos de números de animais confinados ano após ano, devido à oscilação de custos e falta de planejamento. Por exemplo, depois de um ano de margens curtas e altos custos de reposição e milho, muitos produtores não confinaram animais, e o que ocorreu juntamente com exportações estáveis, foram preços poucos sustentados pela falta de animais prontos para o abate, mas com demanda retraída (Tabela 1).

Tabela 1. Retorno sobre investimento de confinamento, com preço travado em bolsa e preço balcão no período de venda

\begin{tabular}{lccc}
\hline & Unidade & $\begin{array}{c}\text { Confinamento 2016 } \\
\text { Bolsa }\end{array}$ & $\begin{array}{c}\text { Confinamento 2016 } \\
\text { Balcão }\end{array}$ \\
\hline Custos & $\mathrm{R} \$$ & 2335,71 & 2335,71 \\
Custo de capital mensal & $\%$ & 0,80 & 0,80 \\
Rendimento de Carcaça & $\%$ & 52 & 52 \\
Preço/peso & $\mathrm{R} \$ \oint^{-1}$ & $165,02^{*}$ & 142 \\
Base & $@$ & 10 & \\
Preço/boi & $\mathrm{R} \$$ boi $^{-1}$ & 2660,14 & 2436,72 \\
\hline Retorno sobre o Investimento & $\%$ & 11,01 & 1,69
\end{tabular}

${ }^{*}$ Preços Maio/2016 para Outubro/2016

Fonte: Cepea (2016c)

Por outro lado, produtores que confinaram, mesmo com altos custos, mas travaram o preço futuro, conseguiram margens positivas com a atividade.

\section{Custos de Produção}

Apesar da inflação ultrapassar os dois dígitos em 2015 e desacelerar em 2016, o desemprego em alta, da retração da economia, das elevadas taxas de juros e do déficit público, agravados pela crise política, que traz instabilidade, desconfiança e dificuldades de propor políticas econômicas críveis, os resultados de 2016 indicam que o setor pecuário seguiu um pouco mais otimista que outros do País nos últimos anos em termos de preços, apesar do custo manter a tendência de alta. 
De acordo com dados do Cepea (2016c), o Custo Operacional Efetivo [COE], composto pelos gastos correntes da propriedade (insumos, mão de obra, operações mecânicas e despesas administrativas), subiu 2,76\% em 2016 (até novembro), considerando-se a "média Brasil" (BA, GO, MG, MT, MS, PA, PR, RS, RO, SP e TO), variação abaixo da inflação do período. A arroba, na média Brasil, subiu 2,05\%. No geral, os insumos que registraram as maiores valorizações de janeiro a novembro (altas acima da inflação) estão atrelados ao dólar, como a suplementação mineral, alguns medicamentos e máquinas e implementos.

Quando analisada a variação acumulada do COE, observou uma alta maior que o preço da arroba nos últimos 13 anos (Figura 3). De 2004 até 2016 o custo operacional efetivo subiu $245,34 \%$, enquanto que a arroba subiu $149,11 \%$.

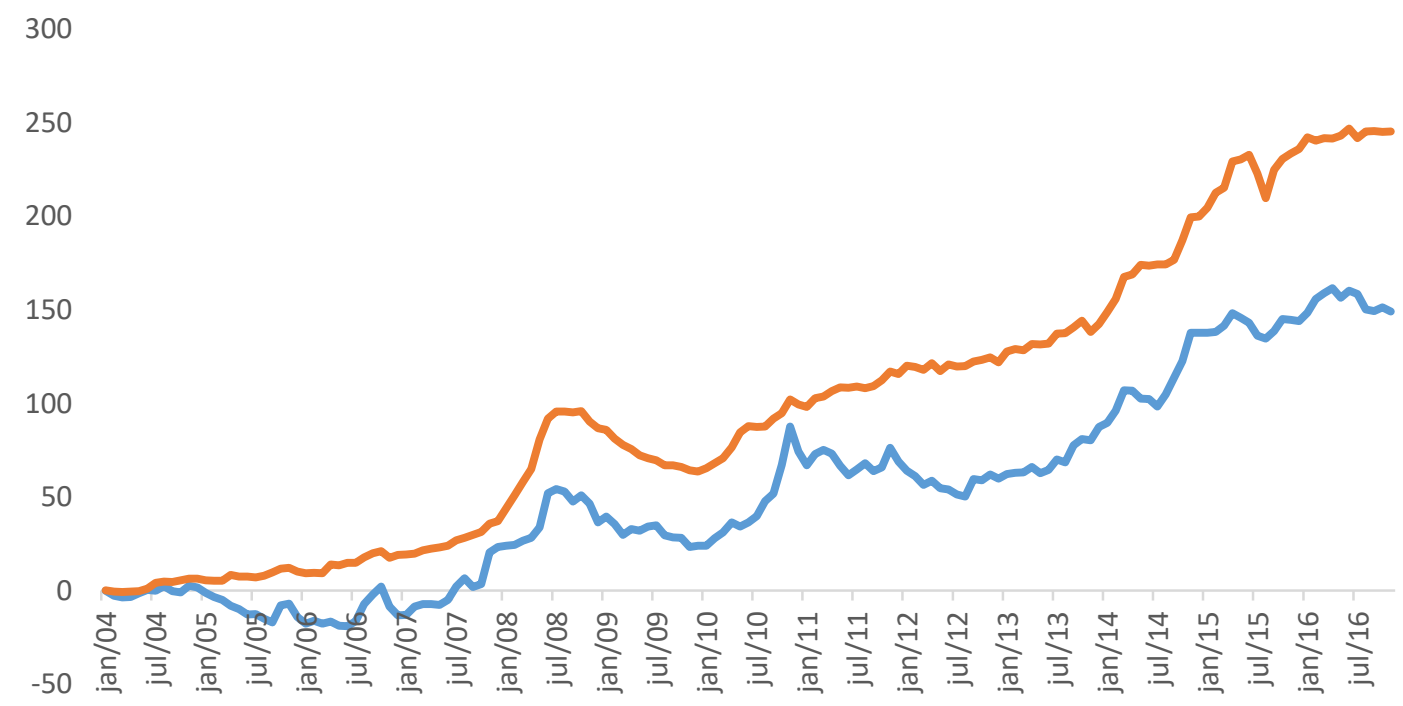

\section{Preço Boi Gordo $\quad$ Custo Operacional Efetivo}

Figura 3. Variação no preço do boi gordo e custo operacional efetivo no período de janeiro/2004 a novembro/2016 - Base $100=$ jan/04

Fonte: Cepea (2016c)

O planejamento adequado da atividade e gerenciamento dos custos (Figura 4) para o melhor uso dos recursos e fatores de produção disponíveis, com o foco em uma maior produtividade, em $\mathrm{kg} \mathrm{ha}^{-1}$, se torna fundamental para uma pecuária de corte sustentável, econômica, social e financeiramente. 


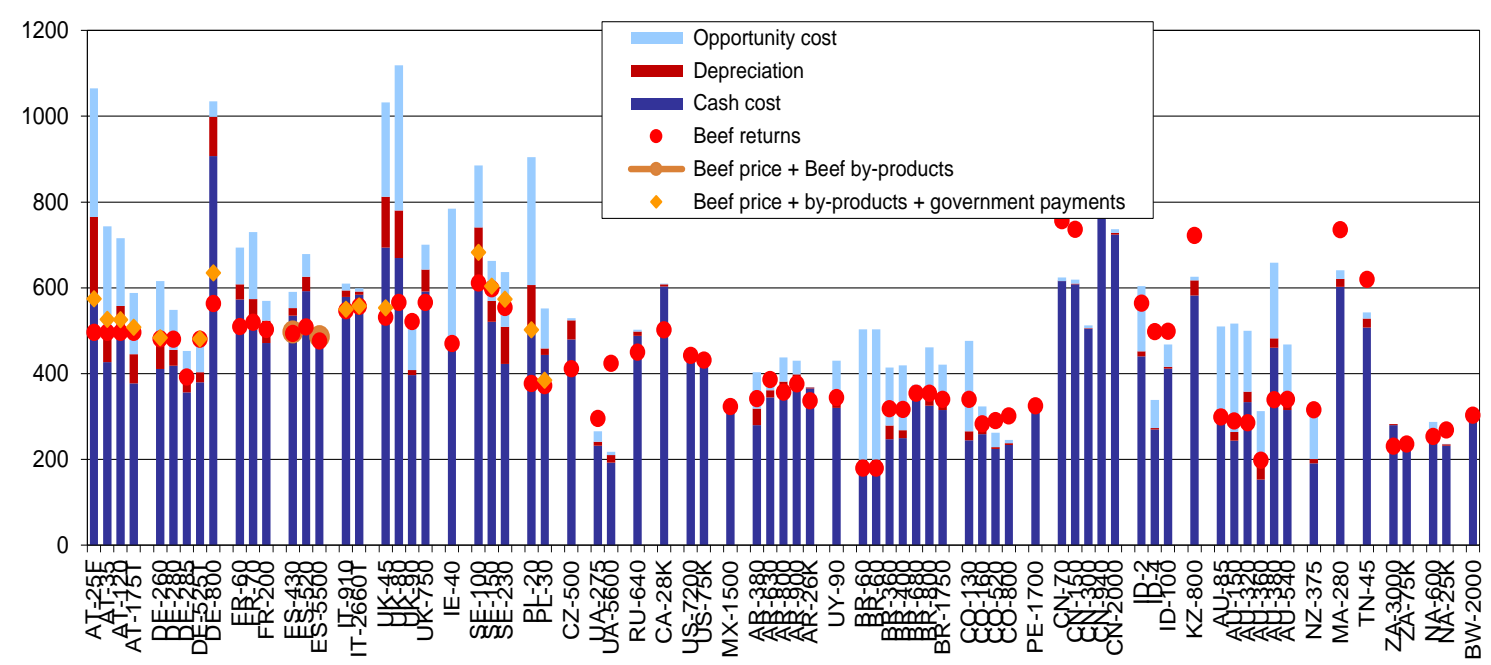

Figura 4. Custo de produção de engorda de bovinos de corte no Mundo - US\$100 kg-1 de peso vivo

Fonte: Agri Benchmark (2015)

Apesar da alta acumulada dos custos, o Brasil é ainda um dos players mundiais com menores custos de produção de carne bovina do mundo.

\section{Relações de Preços}

A oscilação de preços nos mercados, seja por conta de oferta e demanda, seja por políticas econômicas, necessita de uma gestão muito grande por parte dos tomadores de decisão (produtores e frigoríficos) para evitar perdas e auferir mais ganhos.

Até meados dos anos 2000, as transações entre pecuaristas e frigoríficos foram em geral realizadas no mercado spot (Caleman, 2010'; Pitelli e Moraes, 2006; Zucchi, 2010). No período mais recente, identificou a difusão de novas estruturas de governança nas transações entre pecuaristas e indústria frigorífica. Contratos a termo, contratos de longo prazo e integração vertical para trás passaram a coexistir com o tradicional mercado spot, dado o aumento na especificidade do ativo para atender determinados segmentos de mercado e as alterações ocorridas no ambiente institucional (Vinholis et al., 2012; Carrer et al., 2013; Vinholis, 2013²).

O mercado futuro, desde os anos 90, é uma grande ferramenta na garantia de proteção de preços e da produção. Cada vez mais utilizada no Brasil, essa ferramenta

${ }^{1}$ Caleman, S.M.Q. 2010. Falhas de coordenação em sistemas agroindustriais complexos: uma aplicação na agroindústria da carne bovina. 2010. 188 f. Tese de Doutorado em Administração. Universidade de São Paulo, São Paulo, SP, Brasil. ${ }^{2}$ Vinholis, M.M.B. 2013. Fatores determinantes da adoção da certificação SISBOV/TRACES na pecuária de corte. Tese de Doutorado em Engenharia de Produção. Universidade Federal de São Carlos, São Carlos, SP, Brasil. 
tem forte apelo em mercados globais, já que garantem o controle de riscos e o retorno de preços a cada agente do mercado.

As opções para a fixação de preços são o mercado a termo, o mercado futuro propriamente dito e o mercado de opções. O mercado a termo pode ser realizado a preço fixo ou a fixar para a época do abate entre o produtor e a indústria. Nesse tipo de contrato, o produtor não fica exposto aos ajustes diários e os custos do processo são a cargo do frigorífico. Por outro lado, o ganho fica limitado ao termo contratado.

No contrato futuro, a principal diferença é que os contratos são ajustados financeiramente às expectativas do mercado acerca do preço futuro por meio do ajuste diário (que apura perdas e ganhos) e, como consequência, os participantes podem entrar e sair do mercado a qualquer momento. O ajuste diário é uma das grandes diferenças entre o mercado a termo e o futuro. Os contratos futuros são negociados somente em bolsa, e o produtor ou o frigorífico devem fazer os contratos via corretora.

E por último, há o mercado de opções, conhecido como mercado de direitos (compra e venda), o qual permite fixar, hoje, o preço mínimo de venda do boi gordo para a época do abate, além de incrementá-lo através da compra de opção.

Analisando as cotações nos últimos períodos, pelo terceiro ano seguido, os preços em todos os elos da pecuária de corte brasileira estiveram em alta, resultado ainda da baixa oferta causada principalmente pelo clima. Além de as chuvas terem sido abaixo da média de 2013 até meados de 2015 em diversas regiões produtoras, prejudicando as condições das pastagens e, consequentemente, o desenvolvimento e a engorda dos animais, o abate de matrizes em anos anteriores reforçou a queda na disponibilidade interna.

Comparando-se o Indicador Boi Gordo (Cepea, 2016a) - calculado com base nas médias mensais de preços do Estado de São Paulo - com o de 2014, houve valorização real de 7,9\% Para a carne com osso (carcaça casada de boi), no atacado da Grande São Paulo, o aumento foi ainda maior, de 9\%. Esses dados, portanto, mostram que a redução da oferta se sobrepôs à da demanda, em um ano de aumento das taxas de desemprego, de juros e de inflação. O volume de animais abatidos entre janeiro e dezembro foi 4,41\% menor que o do mesmo período de 2014 (IBGE, 2016).

\section{Indústria}

A estabilização da economia nacional com o Plano Real em 1994, trouxe a primeira reestruturação na indústria nacional, que, com o fim da inflação, reduziu o ganho financeiro e ocasionou a falência de mais de 50 frigoríficos pequenos. A paridade 
da moeda nacional frente ao dólar também contribuiu para a queda das receitas da indústria. A Figura 5 retrata o período pós-plano real, quando a margem dos frigoríficos diminuiu, forçando a reorganização do setor. Nota-se que as empresas que trabalham com agregação de valor para a carne (desossa) possuem uma margem superior às empresas que trabalham com carne com osso e vendem a carcaça para terceiros desossarem.

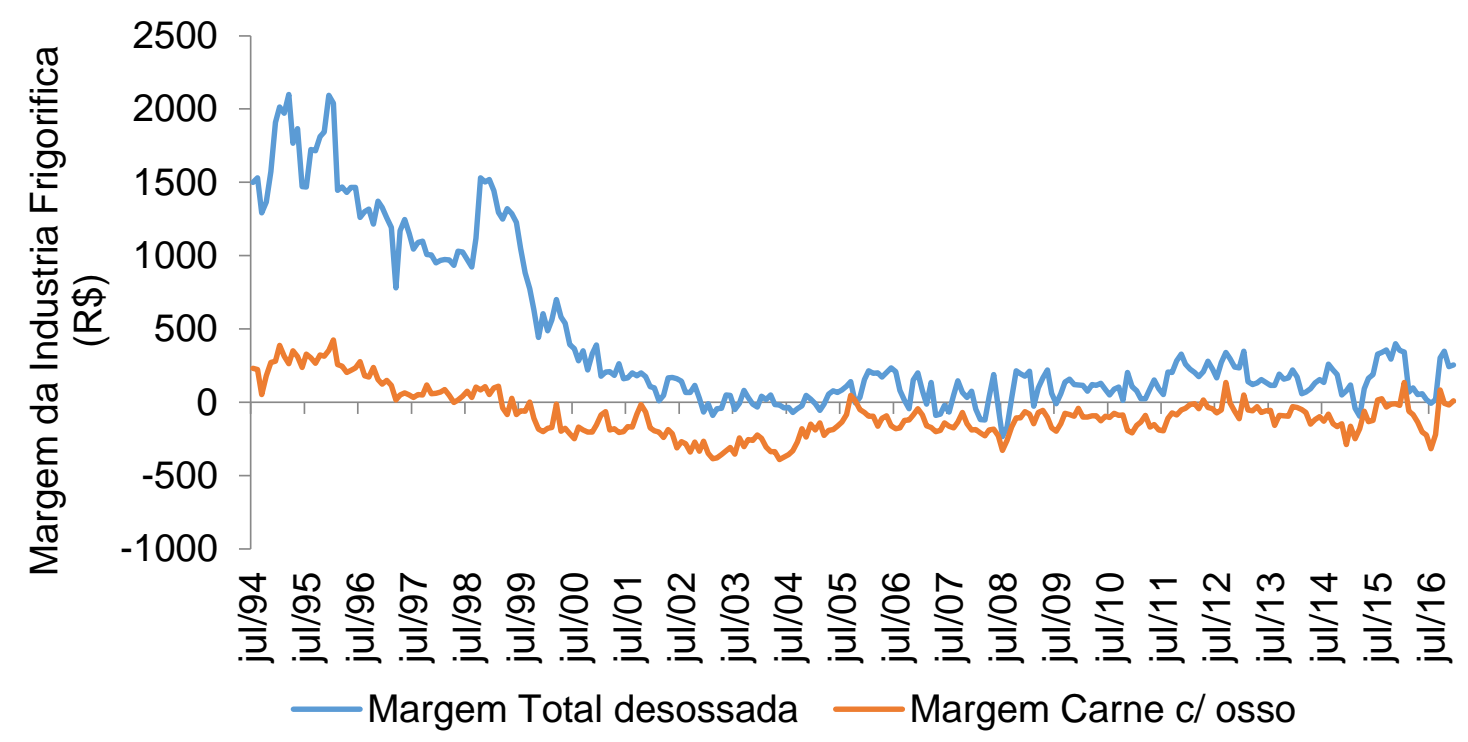

Figura 5. Margem da Indústria Frigorífica de carne bovina com osso e carne bovina desossada - dados mensais, em $\mathrm{R} \$$, de julho/1994 a dezembro/2016 Fonte: Cepea (2016a)

No final dos anos 1990, com a desvalorização cambial, houve crescimento exponencial das exportações, o que trouxe a necessidade de fluxo de caixa para a indústria (pagamento de fornecedores, câmbio e fornecimento de carnes com recebimento a longo prazo). Com a abertura da economia e concorrência com grupos internacionais, houve a necessidade de crescimento nos anos 2000. A busca por recursos se tornou necessária para além do fluxo de caixa, ou seja, financiar investimentos para expansão.

Os dias atuais mostra cada vez mais uma concentração e oligopolização do setor. Esse fator, do ponto de vista econômico, é natural em mercados globalizados, vide exemplos de outros setores (indústria de aviação, indústria farmacêutica, entre outras). Os dados da Tabela 2 consideram somente o abate fiscalizado e com selo SIF, a evolução do número de animais de 2006 a 2014 pelos grandes grupos e sua participação no abate com inspeção federal. Observa-se o grande salto em seis anos 
da participação de apenas quatro grupos no abate total de bovinos no Brasil. Em 2009, representavam cerca de $43 \%$ e, em 2015 , esse número saltou para $56 \%$, configura uma oligopolização do setor de carne bovina nacional. A Tabela 2 mostra também a participação do JBS, maior processadora de carne no Brasil e no Mundo.

Tabela 2. Participação dos grupos de capital aberto no abate anual de animais sifados em relação ao total de abate no Brasil para o período de 2006 a 2015, com destaque para JBS

\begin{tabular}{|c|c|c|c|c|c|c|c|c|c|c|}
\hline & 2006 & 2007 & 2008 & 2009 & 2010 & 2011 & 2012 & 2013 & 2014 & 2015 \\
\hline & \multicolumn{10}{|c|}{ Milhões de cabeça } \\
\hline JBS & 3,41 & 3,62 & 3,90 & 5,92 & 6,48 & 6,92 & 7,37 & 8,68 & 9,38 & 8,29 \\
\hline Marfrig & 2,36 & 2,46 & 2,48 & 1,57 & 2,65 & 2,58 & 2,42 & 2,69 & 2,76 & 2,15 \\
\hline Minerva & 0,79 & 0,91 & 1,04 & 1,29 & 1,44 & 1,69 & 1,71 & 2,01 & 2,13 & 2,28 \\
\hline $\begin{array}{l}\text { BRF } \\
\text { Capital }\end{array}$ & & & & 0,382 & 0,52 & 0,54 & 0,54 & 0,48 & 0,48 & 0,16 \\
\hline $\begin{array}{l}\text { Aberto } \\
\text { Abate Brasil }\end{array}$ & 6,56 & 6,99 & 7,42 & 9,16 & 11,09 & 11,74 & 12,04 & 13,86 & 14,74 & 12,86 \\
\hline SIF & 24,87 & 25,15 & 22,37 & 21,26 & 21,89 & 21,84 & 23,49 & 26,65 & 26,88 & 22,80 \\
\hline $\begin{array}{c}\text { Participação } \\
\text { dos quatro } \\
\text { grupos no } \\
\text { Abate SIF } \\
\text { Total }\end{array}$ & 26,4 & 27,8 & 33,2 & 43,1 & 50,7 & 53,7 & 51,2 & 52,0 & 54,8 & 56,4 \\
\hline $\begin{array}{l}\text { Participação } \\
\text { JBS no Total }\end{array}$ & 13,73 & 14,40 & 17,44 & 27,83 & 29,60 & 31,70 & 31,37 & 32,56 & 34,89 & 36,36 \\
\hline
\end{tabular}

Fonte: JBS (2015); MAPA (2015); Minerva (2015); BRF (2016); Marfrig (2016)

\section{Abate animais}

Nessa nova realidade, somado a questões sanitárias, principalmente a febre aftosa, os frigoríficos procuraram atuar em diferentes regiões do País e em outros países, além de uma nova estrutura financeira, com forte atuação no mercado futuro de boi gordo e câmbio.

A Figura 6 mostra a evolução número de unidades de frigoríficos de carne bovina em cada estado Brasileiro, com Serviços de Inspeção Federal, Estadual e Municipal.

A maior parte dos frigoríficos está localizada nas regiões Sul e Nordeste do País, com a presença, principalmente, de um elevado número de plantas sob fiscalização estadual e municipal ${ }^{3}$.

\footnotetext{
${ }^{3}$ Carvalho, T.B. 2016. Estratégias de crescimento e reestruturação da indústria de carne bovina no Brasil: o papel de políticas públicas discricionárias. Tese de Doutorado em Administração. Universidade de São Paulo, São Paulo, SP, Brasil.
} 


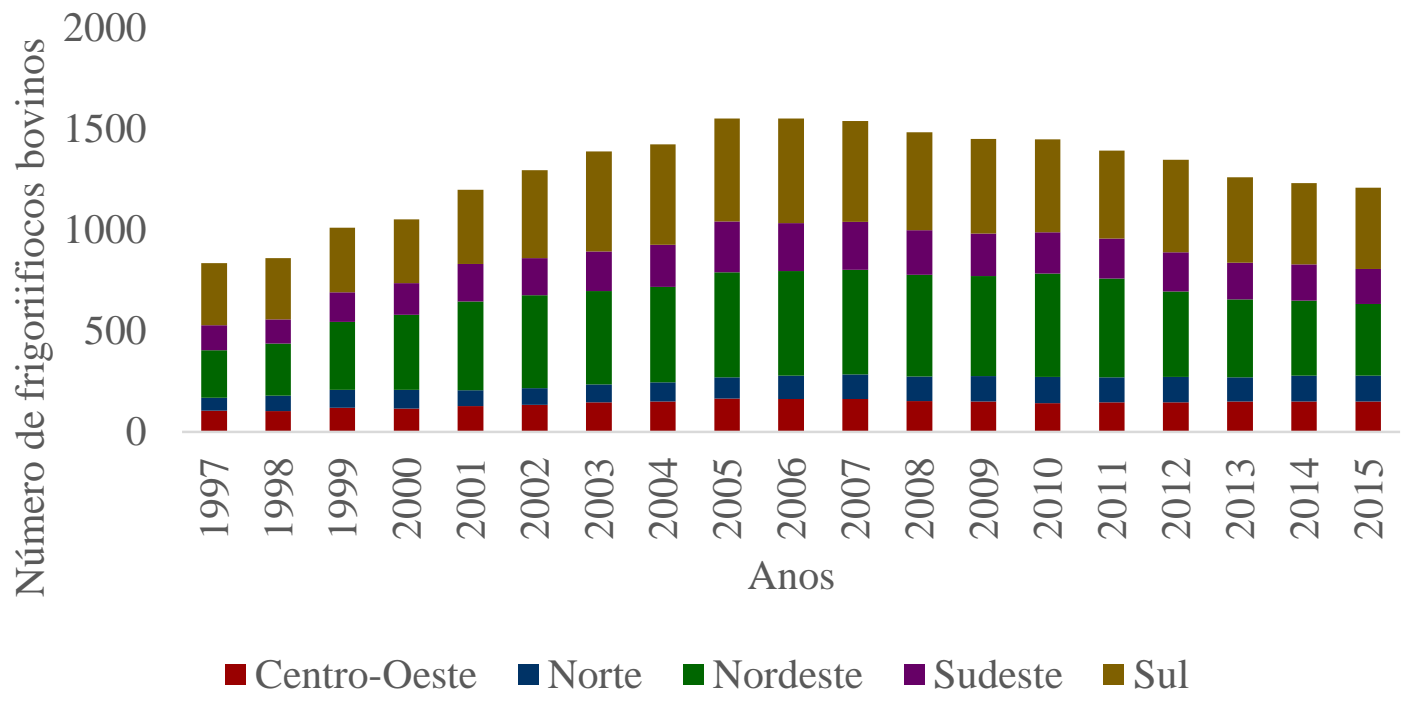

Figura 6. Evolução do número de frigoríficos bovinos com inspeção federal, estadual e municipal nas grandes regiões do território nacional (1997 a 2015)

Fonte: IBGE (2015)

De acordo com o Cepea (2015), o aumento das plantas sob fiscalização foi estimulado, principalmente, pela mudança da forma de tributação, que passou a incidir sobre a carne e não mais sobre os animais. Após aquele crescimento inicial, ocorreu um movimento de ajuste do número de plantas sob fiscalização municipal.

\section{Rendimento de Carcaça}

Um ponto importante na discussão da cadeia está relacionado com o rendimento de carcaça. Um produto melhor acabado e padronizado, no caso o boi, tende a ter um rendimento maior e, consequentemente, uma remuneração maior ao produtor e à própria indústria, que terá mais facilidade de escoar o produto a um preço diferenciado.

A evolução das raças, principalmente a zebuína, somada ao crescente uso do cruzamento industrial, principalmente da raça europeia angus, também vem favorecendo o crescimento de animais mais pesados e com melhores acabamentos.

Deve-se levar em conta também o uso cada vez mais intenso de suplementação e o aumento de confinamentos, que favorecem a padronização da carcaça maior e a redução da vida do animal pronto para o abate.

Todos esses fatores trazem ao produtor um boi de melhor qualidade, padronizado e um rendimento financeiro maior, com preços mais altos e premiações. Pelo lado da indústria, um produto com maior padronização facilita o escoamento e a venda para clientes mais exigentes. Prova disso pode ser observada na Figura 7, que mostra a participação de cortes em uma rede de supermercados. As maiores vendas se 
concentram em cinco cortes, o que mostra que um produto mais padronizado favorece toda a cadeia de venda, agregando valor ao produto.

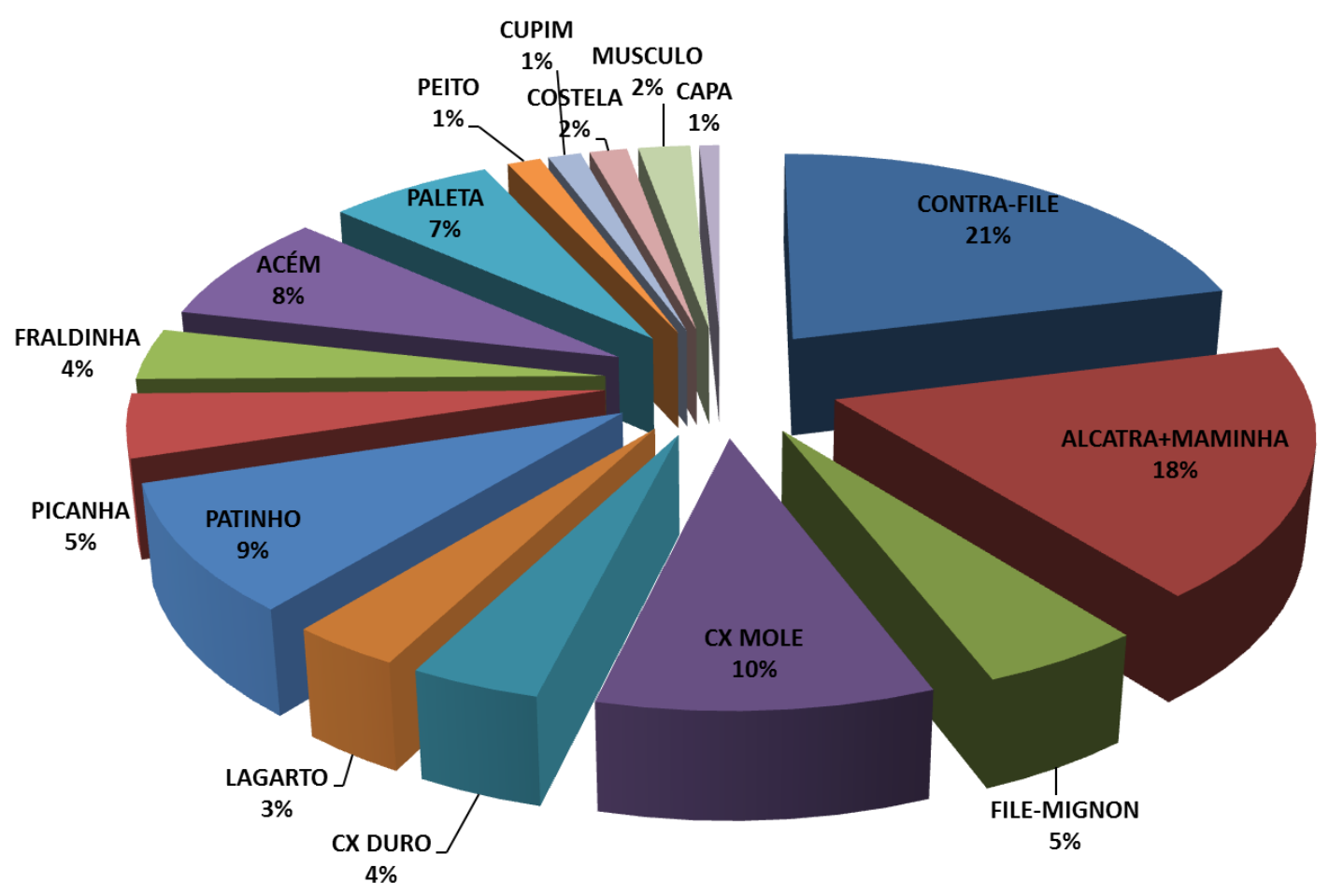

Figura 7. Participação dos cortes de carne bovina em uma rede de supermercados em 2014

Fonte: GPA (2015)

Em resumo, a relação compra e venda entre os envolvidos deve caminhar sempre para uma relação vantajosa para ambas as partes, onde o produtor fornecerá a carne que o mercado demanda e a indústria pagará por esse diferencial, além do lucro.

\section{Mercado internacional}

No mercado internacional é notório o crescimento da participação brasileira com carne bovina, principalmente a partir do final dos anos 90, em função da profissionalização da atividade, rígido controle de doenças, custo baixo, qualidade do produto e desvalorização cambial, tornando-se a partir de 2004, o maior exportador desta carne, posição essa que mantém até os dias atuais. O maior mercado de destino da carne nacional era a União Europeia, até o ano de 2007, quando uma crise de aftosa em 2005 no Brasil e barreiras impostas pela comunidade a fazendas brasileiras nos anos seguintes, fizeram com que outros países ganhassem importância para as vendas 
da carne brasileira, como Rússia, Hong Kong e Egito (Figura 8). O mercado europeu é um importante mercado para a carne brasileira devido aos bons preços que paga pela nossa carne, mas neste atual cenário de escassez de dinheiro há uma preocupação quanto ao montante comprado pelos europeus.

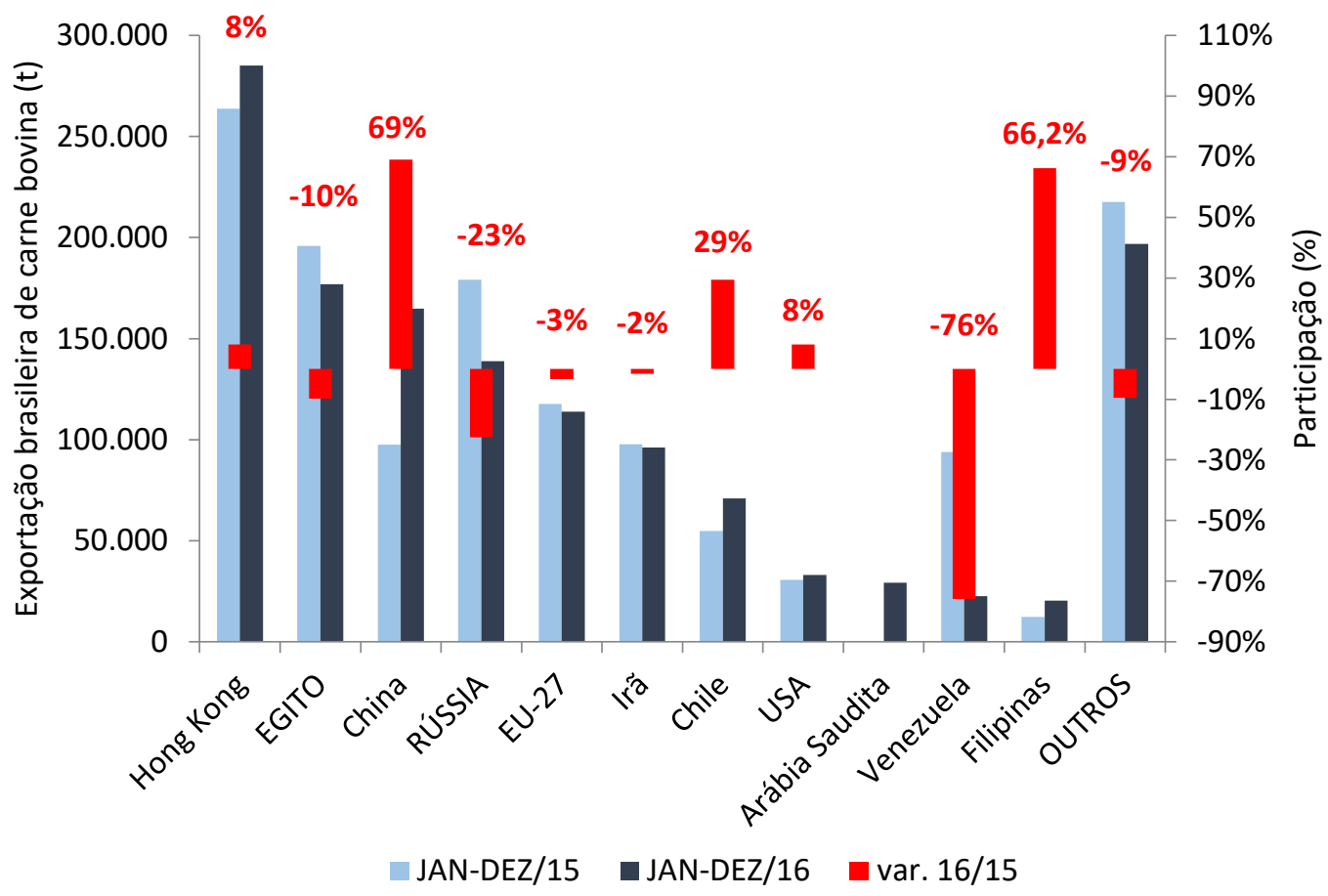

Figura 8. Destino das exportações brasileiras de carne bovina - comparativo $2015 \mathrm{x}$ 2016

Fonte: MDIC (2016)

No comparativo de 2016 frente a 2015, Hong Kong continua sendo o principal destino da carne brasileira, aumentando a demanda em $8 \%$ no comparativo dos dois anos. Esse destino representou mais de $21 \%$ dos embarques brasileiros. Se somado o volume de Hong Kong mais a China, representam juntos $33 \%$ das vendas do Brasil. Destaca no último ano a abertura da Arábia Saudita, se tornando o nono país que mais comprou carne brasileira (considerando os países da União Europeia agrupados).

A figura do mercado internacional na relação entre produtores e indústria deve influenciar no que tange à procura por um animal mais jovem, sadio e padronizado. Barreiras sanitárias e/ou técnicas cada vez mais vem sendo derrubadas e diminuídas devido à necessidade do consumidor estrangeiro na busca por carne mais barata e também pelos esforços do setor na negociação entre países. 
Um fator importante na análise do mercado internacional é a alta competitividade brasileira dentro e fora da porteira. Investidores estrangeiros estão de olho no Brasil em formas de investimentos. No médio e longo prazo, a estabilidade econômica e uma possível menor interferência do governo nas políticas setoriais e no câmbio, devem atrair investimentos de grupos empresariais desde os insumos até os frigoríficos.

\section{Conclusão}

A Pecuária brasileira tem passado por grandes mudanças nos últimos anos. $\mathrm{Na}$ indústria a profissionalização levou as empresas à abertura de capital, a internacionalização, a diversificação das atividades e produtos e, como consequência num mercado oligopolizado, à concentração do setor. Dentro da porteira, o setor produtivo também tem conseguido avanço, no emprego de tecnologias, diversificação de atividades e novas formas de comercialização, com a indústria de insumos e os frigoríficos.

Há no Brasil alguns caminhos a serem seguidos, como acelerar investimentos em capital humano, em novas tecnologias e principalmente em infraestrutura (portos, armazéns e estradas), além do fato de se trabalhar melhor a questão tributária, que em muitos casos faz com que produtos nacionais percam competitividade.

O futuro do mercado de gado de corte, assim como para todo o agronegócio brasileiro é promissor, devido principalmente à disponibilidade de terra e água presentes no território nacional para se produzir carne e ofertar ao mundo. Soma-se a esse fato a perspectiva de possível estabilidade econômica e política, o que favorece investimentos estrangeiros e nacionais no país.

\section{Referências}

Agri Benchmark. 2015. Beef Report. Disponível em: <http://www.agribenchmark.org>. Acesso em: 20 dez. 2016.

Associação Brasileira das Indústrias Exportadoras de Carne [ABIEC]. 2011. Perfil da pecuária brasileira. Disponível em: <http://www.abiec.com.br/Sumario.aspx>. Acesso em: 19 dez. 2016.

Associação Nacional Dos Confinadores [Assocon]. 2016. Notícias. Disponível em: <http://www.assocon.com.br/noticias/>. Acesso em: 17 mar. 2016.

Brasil Foods [BRF]. 2016. Investidores. Disponível em: <http://ri.brfglobal.com/default_pt.asp?idioma=0\&conta=28>. Acesso em: 22 nov. 2016. 
Centro de Estudos Avançados em Economia Aplicada [CEPEA]. 2015. Relatório de Pesquisa: Estudo do Abate Bovino no Brasil. Disponível em: <http://cepea.esalq.usp.br>. Acesso em: 04 jan. 2017.

Centro de Estudos Avançados em Economia Aplicada [CEPEA]. 2016a. Indicadores de Preços Boi. Disponível em: <http://www.cepea.esalq.usp.br/indicador/boi>. Acesso em: 04 jan. 2017.

Centro de Estudos Avançados em Economia Aplicada [CEPEA]. 2016b. PIB agronegócio. Disponível em: <http://cepea.esalq.usp.br/pib/>. Acesso em: 06 jan. 2017.

Centro de Estudos Avançados em Economia Aplicada [CEPEA]. 2016c. Custos e Gestão: Relatório Pecuário. Disponível em:

<http://www.cepea.esalq.usp.br/br/categoria/relatorios-pecuarios.aspx>. Acesso em: 12 jan. 2017.

Grupo Pão de Açúcar [GPA]. 2015. Relatório. Disponível em: <http://www.gpabr.com/pt/>. Acesso em: 20 set. 2015.

Instituto Brasileiro de Geografia e Estatística [IBGE]. 2015. Pesquisa Trimestral de Abate de Animais. Disponível em:

$<w w w . s i d r a . i b g e . g o v . b r / b d a / t a b e l a / l i s t a b l . a s p ? z=t \& 0=1 \& \mathrm{i}=P \& c=1092>$. Acesso em: 05 jan. 2017.

Instituto Brasileiro de Geografia e Estatística [IBGE]. 2016. Produção da pecuária municipal. Disponível em: <www.ibge.gov.br/home/estatistica/economia/ppm/>.

Acesso em: 05 jan. 2017.

JBS Brasil [JBS]. 2015. Relação com Investidores. Disponível em: <http://www2.jbs.com.br/ri/>. Acesso em: 09 nov. 2016.

Marfrig Global Foods [MARFRIG]. 2016. Investidores. Disponível em: <http://www.marfrig.com.br/pt/marfrig-global-foods/historia>. Acesso em: 25 nov. 2016.

Minerva Foods [MINERVA]. 2015. Investidores. Disponível em: $<$ http://ri.minervafoods.com/minerva2012/web/default_pt.asp?idioma=0\&conta=28\&v=. Acesso em: 20 nov. 2015.

Ministério da Agricultura, Pecuária e Abastecimento [MAPA]. 2015. Quantidade de Abate Estadual por Ano/Espécie. Disponível em:

$<$ http://sigsif.agricultura.gov.br/sigsif_cons/lap_abate_estaduais_cons?p_select=SIM>. Acesso em: 15 dez. 2016.

Ministério da Indústria, Comércio Exterior e Serviço [MDIC]. 2016. Estatísticas do Comércio Exterior. Disponível em: <http://www.mdic.gov.br/comercioexterior/estatisticas-de-comercio-exterior>. Acesso em: 04 jan. 2017.

Vinholis, M.M.B.; Souza Filho, H.M.; Carrer, M.J. 2012. Determinants of hybrid forms of governance in the Brazilian beef cattle market. In: Conference on Institutions and Organizations, São Carlos, Brasil. 